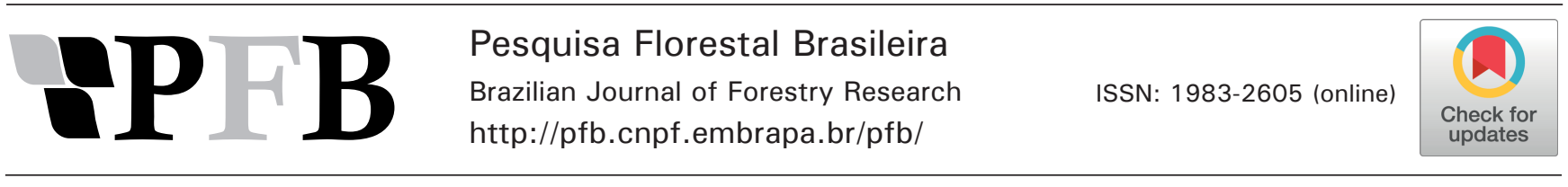

\title{
Parâmetros genéticos para caracteres de crescimento inicial de progênies de bracatinga em Lages, SC
}

\author{
Renata Diane Menegatti ${ }^{1 *}$, Adelar Mantovani $^{1}$, Márcio Carlos Navroski ${ }^{1}$ \\ ${ }^{1}$ Universidade do Estado de Santa Catarina, Av. Luiz de Camões, 2090, CEP 88520-000, Lages, SC, Brasil
}

*Autor correspondente:

renata.d.menegatti@gmail.com

Termos para indexação:

Herdabilidade

Melhoramento florestal

Variabilidade genética

Index terms:

Heritability

Tree breeding

Genetic variability

Histórico do artigo:

Recebido em 11/08/2015

Aprovado em 12/08/2016

Publicado em 30/09/2016

doi: 10.4336/2016.pfb.36.87.1003
Resumo - Objetivou-se com este trabalho estimar parâmetros e valores genéticos para os caracteres diâmetro do coleto e altura, de progênies de bracatinga em fase inicial de desenvolvimento. As sementes foram coletadas de 40 matrizes nativas nos municípios de Abelardo Luz, Chapadão do Lageado, Lages e Três Barras, SC. O teste de progênie foi conduzido na Fazenda Experimental da Universidade do Estado de Santa Catarina, em Lages, visando à seleção de materiais genéticos adaptados à região. $\mathrm{O}$ delineamento utilizado foi o de blocos ao acaso, com quarenta tratamentos (progênies) e 30 repetições, adotando-se dez plantas por parcela em linhas simples. Aos 12 meses de idade, foram avaliados os caracteres: diâmetro do coleto e altura total dos indivíduos. As análises de deviance e as estimativas dos parâmetros genéticos foram realizadas com o programa Selegen-REML/BLUP. Diferenças significativas foram observadas entre procedências e progênies apenas para o caráter diâmetro do coleto. O controle genético dos caracteres avaliados é considerado alto a moderado em nível de plantas individuais e em nível de média de progênies. O caráter diâmetro do coleto mostrou-se mais apropriado para a seleção das matrizes por apresentar maior variação e controle genético.

\section{Genetic parameters for early growth traits in bracatinga progenies in Lages, SC, Brazil}

\begin{abstract}
The aim of this work was estimate genetic parameters and values in the stem diameter and height in Mimosa scabrella progenies at early stages. Seeds were collected from 40 mother trees in Abelardo Luz, Chapadão do Lageado, Lages and Três Barras, in Santa Catarina State. Progenies test was conducted at the Experimental Farm of the Santa Catarina State University, in Lages, SC, aiming at to select genetic materials adapted for the region. It was used ramdomized blocks, with 40 treatments (progeny) and 30 replications, using 10 plants by plot in single line. At 12 months old height and diameter were evaluated. Deviance analysis was performed using Selegen-REML/ BLUP software and genetic parameters were estimated. Significant differences were observed among provenances and progenies. Genetic control of characters is considered low to moderate in individual and family levels. Stem diameter was more appropriate for matrices selection due to its higher variation and genetic control.
\end{abstract}

\section{Introdução}

A alta produtividade madeireira e a boa adaptabilidade caracterizam a espécie Mimosa scabrella Bentham, como uma essência florestal nativa potencial ao uso em reflorestamentos (Mazuchowski et al., 2014). Popularmente conhecida como bracatinga, é uma espécie da família Fabaceae, que apresenta ampla distribuição geográfica, ocorrendo em todo o território do estado de
Santa Catarina e em parte dos outros estados da região Sul e do Sudeste, em Minas Gerais, Rio de Janeiro e São Paulo (Rotta \& Oliveira, 1981; Dutra \& Morim, 2015). A distribuição desta espécie atinge altitudes compreendidas preferencialmente entre 400 a $1.000 \mathrm{~m}$ (Carvalho, 1994), onde as temperaturas médias anuais ficam em torno de $13{ }^{\circ} \mathrm{C}$ a $18,5^{\circ} \mathrm{C}$, sem déficit hídrico (Rotta \& Oliveira, 1981). 
De crescimento rápido e incremento médio anual podendo atingir até $36 \mathrm{~m}^{3} \mathrm{ha}^{-1}$ ano $^{-1}$, quando empregadas técnicas de manejo (Centro Agronômico Tropical de Investigación y Enseñanz, 1996), M. scabrella produz madeira de boa qualidade para madeira serrada, aglomerados e compensados (Carvalho, 1994; Mazuchowski et al., 2014), além de apresentar grande potencial energético (Friederichs et al., 2015). Porém, a produtividade em volume é que constitui um fator fundamental de estímulo para o seu plantio em grande escala. Atualmente, a utilização da espécie em maiores proporções é oriunda do cultivo e manejo por pequenos e médios agricultores em sistemas agroflorestais na região metropolitana de Curitiba, $\mathrm{PR}$, principalmente para utilização como fonte de energia (Souza et al., 2013). O ciclo de corte dos bracatingais (legalizados) gira em torno de 7 a 8 anos para extração de madeira para energia, e de 12 anos para madeira de maior dimensão (Mazuchowski et al., 2014).

No entanto, para se tornar comercialmente viável, tanto para lenha como para fins mais nobres, $M$. scabrella, ainda carece de melhoramento genético (Nascimento, 2010). Informações a respeito da variabilidade genética entre e dentro das populações de ocorrência natural da espécie, além de trabalhos que envolvam a caracterização dos padrões de herança de caracteres de interesse, devem ser priorizados, para que seja possível definir critérios de seleção e recombinação genética, visando à produção de materiais superiores (Mazuchowski et al., 2014).

Entre as variações que podem ser exploradas em programas de melhoramento, que visem o desenvolvimento de materiais genéticos com alto desempenho para a utilização em reflorestamentos, estão aquelas entre e dentro de procedências (Kageyama et al., 1977). O teste de procedências e progênies é uma das estratégias mais empregadas para a quantificação da variabilidade genética existente entre e dentro de populações, permitindo ainda estimar parâmetros genéticos e selecionar os indivíduos de maior desempenho para determinada região (Resende, 2002a). A variabilidade genética existente dentro e entre populações de espécies florestais permite assegurar a escolha das melhores fontes de sementes disponíveis que ocorrem em diferentes origens geográficas da espécie (Torggler, 1987).

Os testes de procedências e progênies, além de auxiliarem na determinação dos parâmetros genéticos e fenotípicos, permitem quantificar a herança dos caracteres de interesse e predizer ganhos esperados com a seleção (Resende, 2002a). Dentre os diversos parâmetros genéticos estimados em testes de progênies, o coeficiente de herdabilidade tem maior importância, pois é ele que expressa o quanto da variância total é atribuída ao efeito do genótipo, em outras palavras, ele revela a precisão no acesso à variação genética verdadeira a partir da variação fenotípica observada nos caracteres avaliados (Borém \& Miranda, 2005).

Atualmente, a metodologia REML/BLUP (máxima verossimilhança restrita/melhor predição linear não viciada) está entre os métodos mais utilizados para a obtenção de estimativas dos parâmetros genéticos e fenotípicos para as espécies florestais, principalmente pela precisão que confere às estimativas obtidas de ensaios desbalanceados (Costa et al., 2000; Resende, 2002a; Kras et al., 2007; Araújo et al., 2014).

Considerando as diversas potencialidades da espécie, o objetivo deste trabalho foi estimar parâmetros e valores genéticos para os caracteres de crescimento inicial entre e dentro de procedências de $M$. scabrella, como subsídio para a seleção de materiais genéticos com desempenho superior para a região do Planalto Serrano do Estado de Santa Catarina.

\section{Material e métodos}

Foram coletadas sementes de 40 matrizes, em dezembro de 2013, em quatro municípios de diferentes regiões do estado de Santa Catarina: Abelardo Luz (Extremo Oeste), Chapadão do Lageado (Vale do Itajaí), Lages (Planalto Serrano) e Três Barras (Planalto Norte) (Figura 1, Tabela 1).

A escolha das matrizes, em cada área de coleta ou procedência, foi baseada nas recomendações prescritas por Sebbenn (2006), priorizando as que dispunham de abundância de frutos e ramificação acima de $2 \mathrm{~m}$. Em cada local foram amostradas 10 árvores matrizes adultas, distanciadas no mínimo de $100 \mathrm{~m}$ entre si, evitando-se a coleta de sementes em árvores com elevado grau de parentesco.

As mudas foram produzidas separadamente por progênie no viveiro da Universidade do Estado de Santa Catarina, em Lages, em março de 2014. Para a produção das mudas foram utilizados tubetes de $290 \mathrm{~cm}^{3}$, contendo, como substrato, casca de pinus decomposta e substrato comercial Tecnomax, na proporção 1:1. 


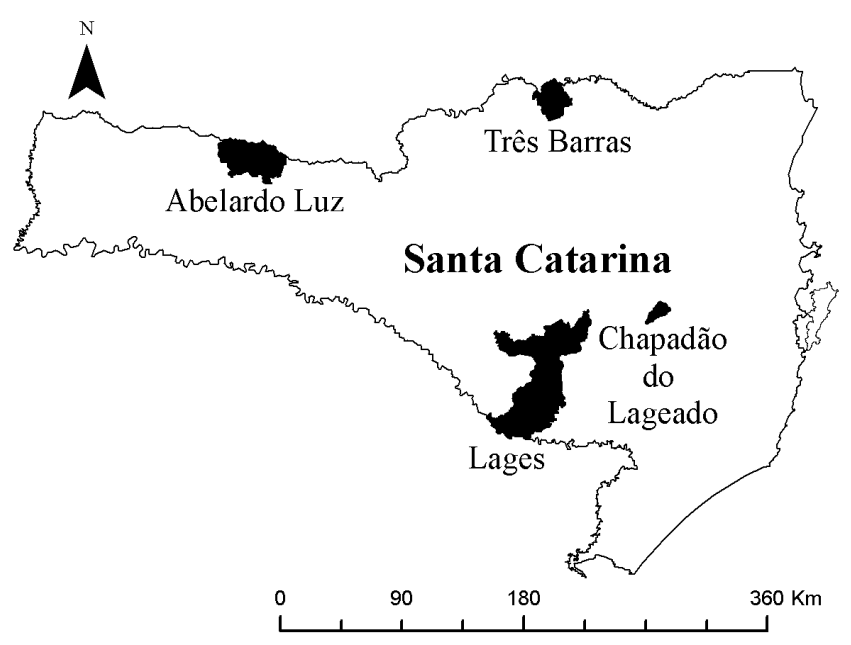

Figura 1. Localização das procedências de Mimosa scabrella utilizadas no teste de progênie, instalado em outubro de 2014, na Fazenda Experimental da Universidade de Santa Catarina, em Lages, SC.

Tabela 1. Coordenadas geográficas e altitude média das quatro procedências de Mimosa scabrella amostradas no estado de Santa Catarina.

\begin{tabular}{|c|c|c|c|}
\hline Procedência & Latitude (S) & Longitude (W) & $\begin{array}{c}\text { Altitude } \\
\text { média (m) }\end{array}$ \\
\hline Abelardo Luz & $36^{\circ} 74^{\prime} 49^{\prime \prime}$ & $70^{\circ} 71^{\prime} 49^{\prime \prime}$ & 760 \\
\hline $\begin{array}{l}\text { Chapadão do } \\
\text { Lageado }\end{array}$ & $64^{\circ} 19^{\prime} 50^{\prime \prime}$ & $69^{\circ} 46^{\prime} 43^{\prime \prime}$ & 570 \\
\hline Lages & $27^{\circ} 51^{\prime} 02^{\prime \prime}$ & $50^{\circ} 12^{\prime} 41^{\prime \prime}$ & 884 \\
\hline Três Barras & $56^{\circ} 97^{\prime} 22^{\prime \prime}$ & $70^{\circ} 97^{\prime} 41^{\prime \prime}$ & 802 \\
\hline
\end{tabular}

Durante sete meses as mudas permaneceram no viveiro recebendo duas irrigações diárias (lâmina de irrigação de aproximadamente $6 \mathrm{~mm}$ diários). Logo após, as mudas foram transplantadas para a área experimental situada na Fazenda da Universidade do Estado de Santa Catarina, em Lages, SC (27\%44'S e $47^{\circ} 4^{\prime} \mathrm{W}$; altitude média $850 \mathrm{~m}$ ). A área de plantio foi preparada utilizando-se o método de subsolagem em linha com profundidade de aproximadamente $40 \mathrm{~cm}$, adubação de cova (50 g por planta do adubo NPK 10-20-10) e controle pré e pós-plantio de formigas cortadeiras.

O delineamento experimental utilizado foi o de blocos ao acaso, com quarenta tratamentos (famílias), 30 repetições e 10 plantas por parcelas em linhas simples, além de uma bordadura dupla em torno de todo o experimento. $\mathrm{O}$ espaçamento utilizado foi de $2 \mathrm{~m} \times 3$ $\mathrm{m}$, totalizando, com a inclusão da bordadura, uma área de aproximadamente 1,2 ha.

Realizou-se a seleção de forma precoce, aos 12 meses de idade, no qual as plantas foram avaliadas quanto aos seguintes caracteres: diâmetro do coleto (DAC), obtido utilizando-se paquímetro e expresso em $\mathrm{mm}$, e altura total (ALT), determinada com auxílio de trena graduada e expressa em $\mathrm{m}$.

A análise dos dados foi realizada pela metodologia de máxima verossimilhança restrita (REML) e o efeito dos tratamentos testado pela análise de deviance (ANADEV), com o auxílio do software Sistema Estatístico e Seleção Genética Computadorizada (SELEGEN) (Resende, 2002b). O método REML foi utilizado para estimar os componentes da variância, devido ao desbalanceamento do número de árvores sobreviventes por parcelas.

Para a estimativa dos parâmetros genéticos da população experimental, considerando avaliações realizadas em nível de indivíduos, foi usado o modelo cinco do software genético-estatístico SELEGEN, desenvolvido por Resende (2002b) para blocos completos, várias populações, progênies de meios irmãos, em um local: $\mathrm{y}=\mathrm{Xr}+\mathrm{Za}+\mathrm{Wp}+\mathrm{Ts}+\varepsilon$, em que: "y" é o vetor de dados; "r" é o vetor dos efeitos de blocos (assumidos como fixos) somados à média geral; "a" é o vetor dos efeitos genéticos aditivos individuais (assumidos como aleatórios); "p" é o vetor dos efeitos de parcelas (assumidos como aleatórios); "s" é vetor dos efeitos de populações ou procedências (aleatórios) e " $\varepsilon$ " é o vetor de erros ou resíduos (aleatórios). As letras maiúsculas representam as matrizes de incidência para os referidos efeitos.

\section{Resultados e discussão}

As progênies de Mimosa scabrella apresentaram, aos 12 meses, um diâmetro do coleto (DAC) médio de $10,04 \mathrm{~mm}$, variando de 9,11 a 11,14 $\mathrm{mm}$, sendo que a maior média foi encontrada para as progênies da procedência de Lages (Tabela 2). As alturas variaram de $0,85 \mathrm{~m}$ a $1,04 \mathrm{~m}$, com média geral para todas as progênies de $0,91 \mathrm{~m}$, tendo novamente as progênies da procedência Lages média superior às demais.

A sobrevivência das mudas no experimento foi diferente entre procedências, sendo que os indivíduos oriundos de Lages, mesmo ambiente em que o plantio foi conduzido, apresentou o maior percentual de sobrevivência (Tabela 2). 
Tabela 2. Características de desenvolvimento inicial, diâmetro do coleto (DAC) e altura total (ALT), de Mimosa scabrella aos 12 meses, considerando quatro procedências instaladas em plantio experimental em Lages, SC.

\begin{tabular}{lccc}
\hline Procedências & DAC $(\mathbf{m m})$ & ALT $(\mathbf{m})$ & Sobrevivência \\
\hline Abelardo Luz & 10,00 & 0,85 & 0,88 \\
Chapadão do & & & 0,86 \\
Lageado & 9,11 & 0,88 & \\
Lages & 11,14 & 1,04 & 0,92 \\
Três Barras & 9,38 & 0,89 & 0,79 \\
\hline Média geral & 10,04 & 0,91 & \\
CV (\%) & 17,87 & 14,83 & \\
\hline
\end{tabular}

É importante ressaltar que o maior desempenho das progênies da procedência de Lages, em relação às médias de DAC e ALT, pode ter ocorrido devido à adaptação do material às condições do ambiente, visto que o material genético é oriundo da região em que o plantio experimental foi conduzido.

Materiais de diferentes locais respondem de forma diferente às condições ambientais e, geralmente, são mais bem adaptados ao local de origem (Cruz et al., 2003), apresentando, frequentemente, desenvolvimento superior (Mazuchowski et al., 2014).

Os coeficientes de variação experimental encontrados foram $17,87 \%$ para o DAC e $14,83 \%$ para a ALT. Estes valores são considerados medianos $(10 \%<\mathrm{CV}$ $\leq 20 \%$ ), segundo classificação de Pimentel-Gomes (1985), indicando boa precisão experimental na obtenção dos parâmetros.

Nascimento (2010) também obteve valores semelhantes para os coeficientes de variação experimental para circunferência à altura do peito (DAP) e ALT (13,3\% e $13,7 \%$, respectivamente), em teste de progênies de $M$. scabrella, aos 5 anos de idade. Sturion et al. (1994), avaliando características de crescimento em teste de procedências e progênies de $M$. scabrella, aos três anos, encontraram valores médios próximos aos encontrados neste trabalho para os coeficientes de variação experimental, sendo 17,3\% e 16,8\% para DAP e ALT, respectivamente.

A análise de deviance (ANADEV) detectou diferenças significativas para o efeito de blocos para os caracteres DAC e ALT (Tabela 3), sugerindo que o delineamento experimental utilizado no teste de procedências e progênies foi eficiente para controlar a heterogeneidade ambiental entre os blocos. A ANADEV também revelou diferenças significativas entre as procedências e progênies para o caráter DAC. Possivelmente, a variabilidade existente pode permitir avanços expressivos em futuros programas de melhoramento genético de M. scabrella.

Tabela 3. Análise de deviance (ANADEV) para os caracteres diâmetro do coleto (DAC) e altura total (ALT), em um teste de procedências e progênies de Mimosa scabrella, aos 12 meses, instaladas em 2014, em Lages, SC.

\begin{tabular}{ccc}
\hline \multirow{2}{*}{ Efeitos } & \multicolumn{2}{c}{ Caracteres } \\
\cline { 2 - 3 } & DAC $(\mathbf{m m})$ & ALT $(\mathbf{m})$ \\
\hline Bloco & $8,36^{*}$ & $2,62^{*}$ \\
Procedências & $121,04^{*}$ & $1,09^{\text {ns }}$ \\
Progênies & $54,45^{*}$ & $0,65^{\text {ns }}$ \\
\hline
\end{tabular}

* = significativo pelo teste $\mathrm{F}(\mathrm{p}<0,05)$.

Considerando que a bracatinga tem grande distribuição na região sul do Brasil (Rotta \& Oliveira, 1981), sugerese que as variações existentes entre as procedências sejam clinais. Variações clinais estão intimamente relacionadas às características fisiológicas de uma espécie (sobrevivência e desenvolvimento) e estas ocorrem de forma contínua em um caráter devido ao gradiente ambiental, como por exemplo a variação em altitude das procedências analisadas. Segundo Shimizu (2007), essas variações podem ser produto de forças genéticas dentro de uma espécie, relacionadas às pressões ambientais, devido às diferentes condições de altitude, edáficas e climáticas, que podem resultar em subpopulações adaptadas a cada condição ambiental específica. Desta forma, sugere-se que a prática de seleção deve explorar a variabilidade entre progênies dentro das procedências para o caráter DAC, pois assim terá maior possibilidade de encontrar materiais com genótipos superiores.

Diversos estudos com espécies arbóreas nativas também evidenciaram variações significativas entre procedências e/ou entre progênies, para diversas características silviculturais, como por exemplo Anadenanthera macrocarpa (Rocha et al., 2002), Eremanthus erythropappus (Silva et al., 2007), Ilex paraguariensis (Kras et al., 2007), Schizolobium amazonicum (Rocha et al., 2009), Handroanthus vellosoi (Batista et al., 2012) e Cedrela fissilis (Navroski et al., 2016). Experimentos compostos por progênies oriundas de procedências distintas, como o do presente estudo, permitem conhecer e avaliar a variabilidade genética existente na espécie, selecionando os genótipos com melhor adaptação aos locais de implantação dos testes. 
Os resultados referentes às estimativas dos parâmetros genéticos para os caracteres DAC e ALT estão apresentados na Tabela 4. As estimativas de herdabilidade individuais no sentido restrito $\left(h^{2} a\right)$ revelaram que para o caráter DAC, a maioria das procedências obteve herdabilidade considerada alta $\left(h^{2}>0,50\right)$, com exceção da procedência de Três Barras $(0,11)$. Isso indica forte controle genético sobre o caráter DAC, e que a seleção em nível de plantas individuais dentro das procedências Abelardo luz, Chapadão do Lageado e Lages, para esta característica, podem resultar em ganhos genéticos.

Para o caráter ALT, as estimativas de herdabilidade individuais foram altas para as procedências de Abelardo Luz $(0,67)$ e Chapadão do Lageado $(0,82)$, ressaltando forte controle genético sobre esse caráter em nível de plantas individuais, principalmente dentro das procedências anteriormente citadas. Em relação às informações de herdabilidade média de progênies, as estimativas para o caráter DAC variaram de 0,47 a 0,75 para as progênies das procedências de Três Barras e Abelardo Luz, respectivamente. Valores considerados altos foram encontrados para o DAC para todas as procedências analisadas, sugerindo que a seleção em nível de famílias para este caráter, independente da procedência, pode resultar em ganhos genéticos significativos. As herdabilidades do caráter ALT variaram de 0,03 a 0,69 para as progênies das procedências de Três Barras e Chapadão do Lageado. Os resultados encontrados têm grande variação, porém são próximos aos observados por Sturion et al. (1994), que encontraram valores de herdabilidade média de progênies variando de 0,36 a 0,76 para o caráter DAP e de 0,07 a 0,46 para o caráter ALT.

Tabela 4. Componentes de variância (REML) para os caracteres diâmetro do coleto (DAC) e altura de planta (ALT), para as procedências Abelardo Luz, Chapadão do Lageado, Lages e Três Barras, de Mimosa scabrella aos 12 meses, em Lages, SC.

\begin{tabular}{|c|c|c|c|c|c|c|c|c|c|c|c|c|c|}
\hline \multicolumn{14}{|c|}{ Componentes de variância } \\
\hline Procedências & Caracteres & $\sigma^{2} a$ & $\sigma^{2}$ parc & $\sigma^{2} e$ & $\sigma^{2} f$ & $h^{2} a$ & $h^{2} m p$ & $C^{2}$ parc & $C^{2}$ proc & $\begin{array}{l}C v g i \\
(\%)\end{array}$ & $\begin{array}{c}\text { Cvgp } \\
\text { (\%) }\end{array}$ & $\begin{array}{l}\text { Cvgi/ } \\
\text { Cvgp }\end{array}$ & $\begin{array}{l}\text { Cve } \\
\text { (\%) }\end{array}$ \\
\hline \multirow{2}{*}{ Abelardo Luz } & $\mathrm{DAC}(\mathrm{mm})$ & 5,48 & 0,5 & 4,85 & 10,84 & 0,53 & 0,75 & 0,05 & - & 23,41 & 11,71 & 2 & 11,83 \\
\hline & ALT (m) & 0,06 & 0,01 & 0,03 & 0,1 & 0,67 & 0,68 & 0,13 & - & 28,72 & 14,36 & 2 & 16,85 \\
\hline \multirow{2}{*}{$\begin{array}{l}\text { Chapadão do } \\
\text { Lageado }\end{array}$} & $\mathrm{DAC}(\mathrm{mm})$ & 4,51 & 0,94 & 3,99 & 9,45 & 0,53 & 0,67 & 0,10 & - & 23,31 & 11,65 & 2 & 14,22 \\
\hline & $\operatorname{ALT}(\mathrm{m})$ & 0,08 & 0,02 & 0,02 & 0,12 & 0,82 & 0,69 & 0,17 & - & 33,16 & 16,58 & 2 & 19,39 \\
\hline \multirow{2}{*}{ Lages } & $\mathrm{DAC}(\mathrm{mm})$ & 9,26 & 1,6 & 7,84 & 18,77 & 0,54 & 0,69 & 0,09 & - & 27,33 & 13,66 & 2 & 15,93 \\
\hline & $\operatorname{ALT}(\mathrm{m})$ & 0,03 & 0,01 & 0,12 & 0,15 & 0,17 & 0,55 & 0,01 & - & 15,31 & 7,65 & 2 & 12,02 \\
\hline \multirow{2}{*}{ Três Barras } & $\mathrm{DAC}(\mathrm{mm})$ & 1,28 & 0,02 & 9,79 & 11,11 & 0,11 & 0,47 & 0,02 & - & 12,07 & 6,04 & 2 & 11,17 \\
\hline & ALT (m) & 0,01 & 0,01 & 0,12 & 0,11 & 0,01 & 0,03 & 0,03 & - & 2,29 & 1,15 & 2 & 11,81 \\
\hline
\end{tabular}

$\sigma^{2} a=$ variância genética aditiva; $\sigma^{2}$ parc $=$ variância de parcela; $\sigma^{2} e=$ variância residual; $\sigma^{2} f=$ variância fenotípica individual; $h^{2} a=$ herdabilidade individual no sentido restrito; $h^{2} m p=$ herdabilidade média de progênies; $C^{2}$ parc = coeficiente de determinação dos efeitos de parcela; $C^{2}$ proc $=$ coeficiente de determinação dos efeitos de populações; $C v g i$ = coeficiente de variação genética aditiva individual; $C v g p=$ coeficiente de variação genotípica entre progênies; $C v g i / C v g p$ = relação entre o coeficiente de variação genética aditiva individual e o coeficiente de variação genotípica entre progênies; $C v e=$ coeficiente de variação experimental.

Nascimento (2010) também obteve valores semelhantes para a herdabilidade média de progênies em teste avaliando nove procedências de $M$. scabrella, encontrando valores de CAP entre 0,15 a 0,80 e para o caráter ALT, 0,02 a 0,72. A ampla variação dos valores de herdabilidade média de progênies, especialmente para a ALT, pode estar relacionada à análise precoce do experimento, ou seja, os indivíduos estão ainda em fase inicial de desenvolvimento.

Quanto ao coeficiente de determinação dos efeitos de parcelas $\left(C^{2}{ }_{\text {arc }}\right)$, foi possível observar na análise individual de cada procedência que todos os valores para este parâmetro foram inferiores a $10 \%$, sendo, segundo Resende (2002a), ideal para estimativas do coeficiente de determinação, o que demonstra que houve baixa variação ambiental entre parcelas e desta forma não houve interferência nas estimativas dos parâmetros genéticos.

Os coeficientes de variação genética, tanto em nível de indivíduo (Cvgi) quanto em nível de progênie ( $C v g p)$ são admitidos como indicadores essenciais da variação existente, permitindo estimar ganhos genéticos em testes 
de procedências e progênies (Kageyama \& Vencovsky, 1983). Os coeficientes de variação genética individual (Cvgi) variaram entre as progênies das procedências avaliadas, sendo os valores mais altos referentes ao DAC encontrados para os indivíduos da procedência de Lages $(27,33 \%)$, seguidos das procedências Aberlado Luz $(23,41 \%)$ e Chapadão do Lageado (23,31\%). Para o caráter ALT os indivíduos da procedência Chapadão do Lageado tiveram os valores mais altos $(33,16 \%)$, seguidos da procedência Abelardo Luz (28,72\%). Os valores mais baixos ( $\mathrm{Cvgi}$ ), para as duas variáveis, foram encontrados para a procedência de Três Barras (2,29\% e $12,07 \%$, DAC e ALT, respectivamente).

De modo geral, podemos inferir que os indivíduos das procedências de Lages e Chapadão do Lageado, por apresentarem valores de $C v g i$ elevados para os dois caracteres, evidenciam a possibilidade de seleção de indivíduos dentro de progênies, devido à presença de variabilidade genética.

Os valores de coeficiente de variação genética de progênie ( $C v g p)$ variaram entre 1,15\% (Três Barras) e $16,58 \%$ (Chapadão do Lageado). Conforme Sebbenn et al. (1998) um coeficiente de variação genético maior que $7 \%$ é considerado alto, sendo possível, portanto, utilizar estes parâmetros como indicativos de sucesso na seleção de materiais genéticos oriundos das progênies das procedências de Abelardo Luz, Chapadão do Lageado e Lages nos programas de melhoramento genético.

A relação $C v g i / C v g p$ estimada para os dois caracteres avaliados, independente da procedência, foi de aproximadamente 2. De acordo com Santos et al. (2014), quando a relação entre o coeficiente de variação dentro de parcelas e o coeficiente de variação entre parcelas for superior a 1, pode-se presumir que existe variação genética a ser explorada dentro das progênies e que a seleção de genótipos de melhor desempenho é favorável.

Os valores do coeficiente de variação experimental (Cve) foram considerados médios para todas as procedências avaliadas, com valor médio de $13,5 \%$ para o DAC e $15 \%$ para a ALT, indicando que o controle experimental foi satisfatório, e que se pode esperar boa precisão nas estimativas de parâmetros genéticos para os caracteres avaliados.

Visto que o presente teste de procedências e progênies foi implantado com o propósito de se tornar um pomar de sementes de bracatinga, sugere-se a seleção individual para o aumento do espaçamento entre as plantas, de forma a contribuir para o bom desenvolvimento da copa dos indivíduos e melhor eficiência na produção de sementes.

A escolha do caráter DAC para a futura seleção das matrizes baseou-se na presença de variabilidade genética significativa entre procedências e também entre progênies e por apresentar maior variabilidade genética e controle genético a ser explorado ao longo de um programa de melhoramento genético.

Para selecionar as matrizes que irão compor o pomar de sementes foi utilizado o critério do número efetivo de indivíduos, ou seja, considerou-se o maior número de indivíduos para assegurar um número efetivo mínimo, que permita a realização de cruzamentos e maior eficiência nas etapas seguintes. Resende (2002a) sugere a utilização do número efetivo mínimo de 30 matrizes como critério quando se deseja recombinações entre plantas perenes e essências florestais. $\mathrm{O}$ critério da seleção do número efetivo mínimo de 30 matrizes também foi citado e empregado por Sturion et al. (1994) no planejamento de um pomar de sementes por mudas para M. scabrella.

A seleção dos 30 melhores indivíduos para o caráter DAC, visando transformar o teste de progênies em pomar de sementes por mudas através do ranking dos melhores indivíduos para o caráter escolhido, está apresentada na Tabela 5, junto aos valores fenotípicos, genéticos aditivos, ganhos genéticos preditos e a nova média das progênies. Pode-se ressaltar que as progênies pertencentes às famílias da procedência de Lages apresentaram melhores desempenhos, pois há um predomínio sequencial dos indivíduos desta procedência entre os trinta melhores indivíduos para o caráter DAC. Desta forma, os indivíduos de Lages, em especial aqueles oriundos das progênies 23 e 24 se mostram promissores, em relação aos demais, para os valores genéticos.

Os ganhos genéticos variaram de $63,8 \%$ a $72,3 \%$, tendo como base o indivíduo 8 da progênie 23 e o indivíduo 9 da progênie 24. Logo, a utilização desses materiais genéticos na sequência do programa de melhoramento genético deve ser estimulada, principalmente se o objetivo for incremento em diâmetro.

Os ganhos genéticos obtidos no presente estudo foram superiores a 4,46 $\mathrm{mm}$ para o DAC. Valores superiores (12,5 mm de DAP) foram encontrados por Sturion et al. (1994) ao praticarem a seleção em materiais genéticos de M. scabrella var. aspericarpa de Bocaiúva do Sul, $\mathrm{PR}$, em análise aos três anos de idade. 
Tabela 5. Valores fenotípicos, genéticos aditivos, ganhos genéticos preditos e nova média da população dos trinta melhores indivíduos para o caráter diâmetro do coleto, em teste de procedências e progênies de Mimosa scabrella, no município de Lages, SC.

\begin{tabular}{|c|c|c|c|c|c|c|}
\hline Procedência & Progênie & Árvore & $\begin{array}{c}\text { Valores } \\
\text { fenotípicos }\end{array}$ & $\begin{array}{c}\text { Valores } \\
\text { genéticos }(\mathbf{u}+\mathbf{a})\end{array}$ & $\begin{array}{c}\text { Ganho } \\
\text { genético }(\mathrm{mm})\end{array}$ & $\begin{array}{l}\text { Nova média da } \\
\text { população }\end{array}$ \\
\hline Lages & 23 & 8 & 22,64 & 16,29 & 6,37 & 16,29 \\
\hline Lages & 24 & 3 & 22,81 & 16,22 & 6,33 & 16,25 \\
\hline Lages & 24 & 4 & 23,24 & 16,17 & 6,31 & 16,23 \\
\hline Lages & 27 & 4 & 22,81 & 15,52 & 6,13 & 16,05 \\
\hline Lages & 28 & 8 & 22,48 & 15,27 & 5,98 & 15,89 \\
\hline Lages & 23 & 2 & 19,76 & 15,22 & 5,86 & 15,78 \\
\hline Lages & 23 & 7 & 19,50 & 15,17 & 5,78 & 15,70 \\
\hline Lages & 23 & 3 & 19,32 & 15,06 & 5,70 & 15,62 \\
\hline Chapadão do Lageado & 17 & 7 & 21,54 & 14,77 & 5,60 & 15,52 \\
\hline Abelardo Luz & 6 & 10 & 20,32 & 14,47 & 5,50 & 15,42 \\
\hline Lages & 23 & 4 & 16,77 & 14,44 & 5,40 & 15,32 \\
\hline Abelardo Luz & 6 & 10 & 20,49 & 14,40 & 5,33 & 15,25 \\
\hline Lages & 26 & 8 & 19,42 & 14,37 & 5,26 & 15,18 \\
\hline Lages & 23 & 9 & 17,20 & 14,27 & 5,20 & 15,11 \\
\hline Lages & 26 & 5 & 18,82 & 14,15 & 5,13 & 15,05 \\
\hline Lages & 23 & 6 & 16,27 & 13,97 & 5,06 & 14,98 \\
\hline Lages & 25 & 9 & 18,81 & 13,92 & 5,00 & 14,92 \\
\hline Lages & 27 & 9 & 18,66 & 13,91 & 4,95 & 14,86 \\
\hline Lages & 28 & 6 & 18,32 & 13,86 & 4,89 & 14,81 \\
\hline Lages & 24 & 4 & 16,45 & 13,85 & 4,84 & 14,76 \\
\hline Lages & 24 & 6 & 16,94 & 13,83 & 4,80 & 14,72 \\
\hline Lages & 23 & 5 & 14,84 & 13,72 & 4,75 & 14,67 \\
\hline Lages & 23 & 8 & 15,45 & 13,67 & 4,71 & 14,63 \\
\hline Chapadão do Lageado & 17 & 6 & 18,42 & 13,59 & 4,67 & 14,59 \\
\hline Lages & 24 & 1 & 16,27 & 13,58 & 4,63 & 14,55 \\
\hline Lages & 23 & 5 & 15,35 & 13,57 & 4,59 & 14,51 \\
\hline Lages & 25 & 8 & 17,69 & 13,56 & 4,56 & 14,47 \\
\hline Lages & 26 & 1 & 17,59 & 13,44 & 4,52 & 14,44 \\
\hline Lages & 23 & 6 & 14,10 & 13,43 & 4,49 & 14,44 \\
\hline Lages & 24 & 9 & 15,84 & 13,39 & 4,46 & 14,38 \\
\hline Média geral (mm) & & & & & & 10,04 \\
\hline
\end{tabular}

A acurácia seletiva, que representa a relação entre o valor genético verdadeiro e o estimado foi $78 \%$. Conforme Resende (2002a), valores ótimos de acurácia são obtidos acima de $75 \%$. Desta forma, os valores encontrados para estes caracteres no teste de progênie revelam boa precisão no acesso à variação genética verdadeira a partir da variação fenotípica observada nos caracteres avaliados.

Por se tratar de uma avaliação realizada a partir da análise das características de indivíduos em 
desenvolvimento inicial (seleção precoce), acreditase que as próximas avaliações poderão confirmar os resultados de desempenho desses materiais para efeito de seleção de material superior de M. scabrella.

\section{Conclusões}

Procedências e progênies de Mimosa scabrella diferem significativamente entre si somente para o caráter diâmetro de coleto.

O controle genético dos caracteres diâmetro do coleto e altura é considerado médio a alto em nível de plantas individuais e de média de progênies, principalmente para o caráter diâmetro de coleto.

O caráter diâmetro do coleto é o mais apropriado para a seleção das matrizes que irão constituir a área de produção de sementes de bracatinga, por apresentar variação entre procedências e progênies e maior controle genético.

\section{Referências}

Araújo, D. et al. Variação genética para caracteres silviculturais em progênies de polinização aberta de Astronium graveolens Jacq. (Anacardiaceae). Cerne, v. 20, n. 1, p. 61-68, 2014. DOI: 10.1590/ S0104-77602014000100008.

Batista, C. M. et al. Estimativas de parâmetros genéticos e a variabilidade em procedências e progênies de Handroanthus vellosoi. Pesquisa Florestal Brasileira, v. 32, n. 71, p. 269-276, 2012. DOI: 10.4336/2012.pfb.32.71.269.

Borém, A. \& Miranda, G. V. Melhoramento de plantas. 4. ed. Viçosa, MG: UFV, 2005. 525 p.

Carvalho, P. E. R. Espécies florestais brasileiras: recomendações silviculturais, potencialidades e uso da madeira. Colombo: EMBRAPA-CNPF; Brasília, DF: EMBRAPA-SPI, 1994. 640 p.

Centro Agronômico Tropical de Investigación y Enseñanza (Turrialba, Costa Rica). Mimosa scabrella: silvicultura de espécies promisorias para producción de leña em America Central: resultados de cinco años de investigación. Turrialba, 1996. p. 205-210.

Costa, R. B. et al. Selection and genetic gain in rubber tree (Hevea) populations using a mixed mating system. Genetic and Molecular Biology, v. 23, n. 3, p. 671-679, 2000. DOI: 10.1590/ S1415-47572000000300028.

Cruz, C. D. et al. Modelos biométricos aplicados ao melhoramento genético. Viçosa, MG: UFV, 2003. v. 2. 585 p.

Dutra, V. F. \& Morim, M. P. Mimosa in lista de espécies da flora do Brasil. Rio de Janeiro: Jardim Botânico do Rio de Janeiro, [2015]. Disponível em: <http://floradobrasil.jbrj.gov.br/jabot/floradobrasil/ FB100978>. Acesso em: 13 maio 2015.
Friederichs, G. et al. Qualidade da madeira e do carvão vegetal de bracatinga (Mimosa scabrella Benth.). Revista Ciência da Madeira, v. 6, n. 2, p. 79-87, 2015. DOI: 10.12953/2177-6830/ rcm.v6n2p79-87.

Kageyama, P. Y. et al. Variação genética entre e dentro de progênies de Pinus patula Schiede e Deppe na região de Telêmaco BorbaPR. Instituto de Pesquisa Florestal, n. 15, p. 21-39, 1977.

Kageyama, P. Y. \& Vencovsky, R. Variação genética em progênies de uma população de Eucalyptus grandis (Hill) Maiden. Instituto de Pesquisa Florestal, v. 24, p. 9-26, 1983.

Kras, S. M. et al. Vigor juvenil em progênies de erva-mate (Ilex paraguariensis A. St.-Hil.) nativas do estado de Mato Grosso do Sul. Ciência Florestal, v. 17, n. 1, p. 33-41, 2007.

Mazuchowski, J. Z. et al. ; Bracatinga, Mimosa scabrella Bentham: cultivo, manejo e usos da espécie. Florianópolis: Epagri, 2014. 365 p.

Nascimento, A. G. Parâmetros genéticos obtidos por modelos mistos em progênies e procedências da Mimosa scabrella Bentham (bracatinga). 2010. Dissertação (Mestrado em Ciência) - Escola Superior de Agricultura Luiz de Queiroz, Piracicaba.

Navroski, M. C. et al. Procedência e adubação no crescimento inicial de mudas de cedro. Pesquisa Florestal Brasileira, v. 36, n. 85, p. 17-24, 2016. DOI: 10.4336/2016.pfb.36.85.966.

Pimentel-Gomes, F. Curso de estatística experimental. São Paulo: ESALQ, 1985. 467 p.

Resende, M. D. V. Genética biométrica e estatística no melhoramento de plantas perenes. Brasília, DF: Embrapa Informação Tecnológica; Colombo: Embrapa Florestas, 2002a. 975 p.

Resende, M. D. V. Software Selegen-REML/BLUP. Colombo: Embrapa Florestas, 2002b. 67 p. (Embrapa Florestas. Documentos, 77).

Rocha, R. B. et al. Avaliação genética de procedências de bandarra (Schizolobium amazonicum) utilizando REML/BLUP (Máxima verossimilhança restrita/Melhor predição linear não viciada). Scientia Forestalis, v. 37, n. 84, p. 351-358, 2009.

Rocha, M. G. B. et al. Teste de procedências e progênies de angico vermelho (Anadenanthera macrocarpa (Bentham) Brenan). In: Rocha, M. G. B. Melhoramento de espécies arbóreas nativas. Belo Horizonte: DDFS/Instituto Estadual de Florestas, 2002. p. 41-55.

Rotta, E. \& Oliveira, Y. M. M. Área de distribuição natural da bracatinga (Mimosa scabrella Bentham). In: SEMINÁRIO SOBRE ATUALIDADES E PERSPECTIVAS FLORESTAIS, 4., 1981, Curitiba. "Bracatinga: uma alternativa para o reflorestamento": anais. Curitiba: EMBRAPA-URPFCS, 1981. p. 1-23.

Santos, L. de S. et al. Variabilidade genética entre e dentro de progênies de ipê rosa (Handroanthus avellanedae) (Lorentz ex Griseb.) Mattos (Bignoniaceae). Revista Global Science and Technology, v. 7, n. 2, p. 98-105, 2014.

Sebbenn, A. M. et al. Parâmetros genéticos na conservação da Cabreúva - Myroxylon peruiferum L.F. Allemao. Scientia Forestalis, n. 53, p. 31- 38, 1998. 
Sebbenn, A. M. Sistemas de reprodução em espécies tropicais e suas implicações para a seleção de árvores matrizes para reflorestamentos ambientais. In: Higa, A. R. \& Silva, L. D. (Coord.). Pomar de sementes de espécies florestais nativas. Curitiba: FUPEF, 2006. p. 93-138.

Shimizu, J. Y. Estratégia complementar para conservação de espécies florestais nativas: resgate e conservação de ecótipos ameaçados. Pesquisa Florestal brasileira, n. 54, p. 07-35, 2007.

Silva, A. C. et al. Variação genética entre e dentro de populações de candeia (Eremanthus erythropappus (DC.) MacLeish). Ciência Florestal, v. 17, p. 271-277, 2007.
Souza, R. F. et al. Modelagem de carbono orgânico total e da lenha por unidade de área para bracatingais nativos. Ciência Florestal, v. 23, n.1, p. 117-127, 2013. DOI: 10.5902/198050988446.

Sturion, J. A. et al. Variação genética e seleção para características de crescimento em um teste de progênie de Mimosa scabrella var. aspericarpa. Boi. Pesquisa Florestal brasileira, n. 28-29, p. 7383, 1994.

Torggler, M. G. F. Variação genética entre progênies dentro de procedências de Eucalyptus saligna Smith. 1987. Dissertação (Mestrado em Agronomia) - Escola Superior de Agricultura Luiz de Queiroz, Piracicaba. 
